\title{
Caracterización del componente fraseológico en el discurso periodístico español ${ }^{1}$
}

\author{
Characterization of the phraseological component in the Spanish journalistic discourse \\ Ángel Cervera Rodríguez ${ }^{2}$
}

Fecha de recepción: 17-8-2019

Fecha de aprobación: 7-10-2019

\begin{abstract}
Resumen
Esta investigación se centra en explicar el componente léxico-fraseológico presente en el discurso periodístico español. Tiene por objeto explicar los aspectos lingüísticos y el carácter pragmático que adquieren estas unidades en el discurso periodístico. En ellas se incluyen las pertenecientes al «discurso repetido», como las frases hechas, las locuciones, las expresiones idiomáticas fosilizadas en forma de enunciados y las que están en proceso de formalización léxico-sintáctica. Para ello, se ha aplicado una metodología basada en el análisis lingüístico-pragmático de un corpus de unidades fraseológicas representativas extraídas de diferentes medios de comunicación. Así se ha podido abordar la problemática de la fraseología, al tiempo que se ha podido identificar el grado de fijeza léxica y comprobar el constante recurso a estas unidades, sobre todo verbales, con proyección pragmático-discursiva en el discurso periodístico.
\end{abstract}

Palabras clave: unidad fraseológica, léxico fraseológico, idiomaticidad, discurso periodístico, pragmática.

\begin{abstract}
This research focuses on explaining the lexical-phraseological component present in the Spanish journalistic discourse. Its purpose is to explain the linguistic aspects and the pragmatic character acquired by these units in journalistic discourse. In them there are included the ones belonging to the "repeated speech", as the set phrases, the phrases, the idiomatic expressions become fossilized in the shape of terms of reference and those who are in process of lexical - syntactic formalization. For this, we applied a methodology based on the linguistic - pragmatic analysis of a corpus of phraseological units representative extracted from different mass media. This way one could have approached the problematics of the phraseology, at the time that one could have identified the degree of lexical firmness and to verify the constant resource to these units, especially verbal, with pragmatic discursive projection in the journalistic speech.
\end{abstract}

Key words: phraseological unity, phraseological lexicon, idiomaticity, journalistic discourse, pragmatics.

1 Este artículo de investigación se inserta en el grupo "Lingüística aplicada al análisis del discurso oral y escrito en español” y está vinculado al proyecto de Referencia: PR26/26-20258, subvencionado por la Universidad Complutense de Madrid y el B. de Santander.

2 El autor es doctor en Filología y Profesor Titular de Universidad en el Departamento de Lengua Española y Teoría de la Literatura, Facultad de Filología, Universidad Complutense de Madrid. (España). Sus líneas de investigación son, principalmente, Gramática, Semántica, Lexicología, Pragmática y Análisis del discurso oral y escrito en español. Correo electrónico: cervera1@filol.ucm.es 


\section{Introducción}

El léxico fraseológico se conforma como una forma léxica integrada por dos o más palabras con significado unitario. Se caracteriza por su frecuencia de uso, su fijación e idiomaticidad, de cuyo estudio se encarga la fraseología, la lexicología, la semántica, la gramática y la pragmática. En este trabajo se pretende explicar el valor léxico-semántico de las unidades fraseológicas (UFs), como parte integrante del léxico-fraseológico en el discurso periodístico. Se trata de observar el grado de fijación de las expresiones fraseológicas, teniendo presente la idea de Zuluaga (1980, p. 124) de que toda expresión idiomática es fija, por lo que la idiomaticidad presupone la fijación.

El proceso de formalización con que cuenta la lengua lleva a la lexicalización ${ }^{3}$ de frases hechas y palabras integradas en expresiones idiomáticas fosilizadas o unidades fraseológicas con diferentes grados de fijación, formando parte del «discurso repetido», en terminología de Coseriu (1986, p. 144). Este potencial dinámico y creativo de la lengua se manifiesta en la revitalización de las UFs tanto en el discurso oral como en el escrito, especialmente en el periodístico ${ }^{4}$, de gran interés para conocer la recurrencia léxico-fraseológica ${ }^{5}$ en la lengua actual. Y, dentro del repertorio léxico-fraseológico ${ }^{6}$ empleado de forma frecuente en el discurso periodístico están los compuestos sintagmáticos ${ }^{7}$, las colocaciones, los enunciados fraseológicos y las expresiones verbales fijas y semifijas que se caracterizan por su polivalencia formal y significativa.

\section{El componente léxico-fraseológico en el discurso periodístico}

El periodista elabora los mensajes periodísticos con unas determinadas intenciones comunicativas. A su vez, es normal que en todas las manifestaciones discursivas periodísticas esté presente la expresión fraseológica, sobre todo en los géneros de opinión -artículo, editorial, columna y cartas-; en las entrevistas, de género informativo, mediante la fórmula de pregunta-respuesta; y en los titulares, como reclamo anticipador del texto. Entre los rasgos que caracterizan las expresiones o unidades fraseológicas, apunta Romero (2007, p. 9o6), están: a) la estabilidad semántico-sintáctica, que constituye el aspecto formal que permite identificar las UFs, mediante la combinación fija y determinada de palabras ligada a la variabilidad de las UFs, puesto que sus componentes tienen la posibilidad de cambio, aunque Rivas (2004, p. 728) entiende que la fijación gramatical de los componentes en las UFs no admite variaciones morfológicas ni determinaciones sintácticas, es decir, solo admite la determinación que afecta al conjunto de

3 El grado de formalización del léxico fraseológico viene dado por la relación que se establece entre léxico y sintaxis. Por ello, conviene clarificar los conceptos de gramaticalización, lexicalización y fraseologización. Con gramaticalización se hace referencia, señala Elvira (2006), a procesos de cambio variados, siempre y cuando estos cambios representen una incorporación o novedad en el listado de estructuras, categorías, funciones, rasgos, unidades, etc., de la gramática de una lengua, al tiempo que se concibe como un proceso de pérdida de autonomía léxica. El concepto de lexicalización lo relaciona Ruiz Gurillo (1997a, p. 102) con idiomaticidad, definido como un procedimiento por el que lexemas complejos tienden a convertirse en unidades léxicas simples perdiendo su carácter sintagmático, es decir, la pérdida de caracteres gramaticales en beneficio de la unión integradora de los componentes. Y la fraseologización, según Ruiz Gurillo (1997a, p. 103), es el proceso por el que, gracias a la fijación en algún grado y a la idiomaticidad -parcial o total-, se constituye una unidad fraseológica.

4 El corpus procede de varios periódicos impresos y digitales y medios audiovisuales actuales: El País, El Mundo, ABC, El Periódico, La Razón, Libertad Digital (LD), El Confidencial, El Plural, Marca, TVE, La Sexta y la SER.

5 El léxico-fraseológico abarca el conjunto de unidades fraseológicas de las que da cuenta la Fraseología, que estudia las fijaciones léxicas de una lengua equivalentes a palabras simples por su función y significado tanto en el sistema como en el uso.

6 Los términos "expresión fraseológica" y "unidad fraseológica" se utilizan indistintamente para referirse a combinaciones de dos o más palabras integradas de forma unitaria y fijas en el sistema de la lengua.

7 Los compuestos sintagmáticos (o pluriverbales) se consideran unidades fraseológicas o expresiones fijas, a diferencia de los sintagmas libres y de las colocaciones, definidas por Corpas (1996, p. 20), como "unidades léxicas integradas por dos o más palabras dotadas de significado unitario". 
la unidad fraseológica, no a las partes; b) la idiomaticidad ${ }^{8}$, que es otra propiedad fraseológica referida a la desigualdad entre la suma de los elementos de que se compone la unidad fraseológica y su significado global; y c) la lexicalización, considerada como la pérdida de caracteres gramaticales en favor de la fusión de sus componentes; además, está relacionada con reproducibilidad ${ }^{9}$ de las UFs, como señala Zuluaga (198o, p. 26), por la frecuencia de uso con la que cuentan los hablantes. No obstante, los resultados de la lexicalización hay que separarlos de los mecanismos idiomáticos presentes en las UFs. Zuluaga (1980, p. 125) señala al respecto que hay casos de lexicalización en la formación de palabras, como el de la composición, procedimiento de combinaciones idiomáticas que conforman unidades léxicas integradas. Aun así, no es fácil establecer límites rígidos entre unidades que constituyen el léxico fraseológico.

Al igual que sucede con el léxico de palabras individualizadas en general, el fraseológico procede de códigos variados -político, judicial, económico, comercial, cultural, literario, etc.-, pero principalmente de la lengua común y coloquial, que cuenta con estructuras sintácticas y procedimientos de asociación y de transposición léxicosemánticas muy diversos, que permiten al hablante ampliar el campo designativo y simbólico con el fin de conocer e interpretar la realidad representada, como podemos ver en la siguiente construcción con el verbo "dar" de gran producción fraseológica: (1) El equipo de Zidane da un golpe en la mesa en el Camp Nou y recupera moral y coraje para la Champions (El País, 3/4/16).

El enunciado del ejemplo 1 es una construcción coordinada en la que el $1^{\circ}$ predicado formado con Vtr.+CD "da un golpe en la mesa” responde a una unidad fraseológica formalizada por metaforización con sentido hiperbólico, que se utiliza para decir que el Real Madrid ganó con autoridad el partido contra el Barcelona, de lo que se infiere que ya puede competir al mismo nivel, al tiempo que puede equivaler a una colocación en cuanto a que cabe variar la expresión "dar un golpe en/sobre/encima de la mesa / el tapete / de mano, de efecto, de pecho, etc." con significados pragmáticos diferentes. Sin embargo, los componentes del $2^{\circ}$ predicado "recupera moral y coraje" mantienen su independencia significativa por lo que no forman una unidad fraseológica.

Se constata así que, al analizar el léxico fraseológico, hemos de fijarnos, como explica Martínez López (1995, pp. 198-239), en los aspectos morfosintácticos, léxico-semánticos y pragmáticos. Asimismo, Mellado Blanco (2004, pp. 25-27) explica la fraseología desde una perspectiva morfosintáctica y semántica, ajustándola a tres niveles:

a) Nivel 1: significado primario y directo de los componentes por separado; b) Nivel 2: significado recto o literal, resultado de la suma de cada uno de los componentes del fraseologismo; y c) Nivel 3: significado fraseológico global, es decir, el conjunto de significados fraseológicos de una lengua de acuerdo con principios onomasiológicos (campos conceptuales). Ahora bien, de acuerdo con el valor funcional, indica Rivas (2004, p. 729), las unidades fraseológicas pueden establecerse en el nivel de palabra, sintagma, oración o texto. No obstante, los niveles en los que mejor se representan son el sintagma y la oración, al estar constituidas normalmente por la integración de dos o más palabras dotadas de un significado unitario. Así, se tiene en cuenta el aspecto sintáctico para distinguir las locuciones y las colocaciones, pertenecientes al nivel suboracional, y los enunciados fraseológicos, al nivel oracional. Se hablaría, pues, de fraseologismos, caracterizados por ser total o parcialmente idiomáticos, tener capacidad modificadora, como las colocaciones, y tratarse de unidades categoriales, como las locuciones nominales, adjetivas, verbales, adverbiales, etc.

8 Ruiz Gurillo (1997a, p. 100) define la idiomaticidad fraseológica como "la combinación fija de palabras que disfruta de un significado no composicional, ocasionado por recursos como la metáfora, la hipérbole, etc. y de una motivación graduable que depende tanto de las relaciones internas que establezca con el significado originario de sus componentes, como de las conexiones externas contextuales".

9 La “reproducción”, término utilizado por Zuluaga (1980, p. 26), es un tipo de repetición que actúa como procedimiento mediante el que se construyen algunas unidades fraseológicas (Ruiz Gurillo, 1997a, p. 88). A este respecto, Escandell (1991, p. 72) habla de la repetición voluntaria de un constituyente (o reduplicación léxica) dentro de una unidad sintáctica con el fin de modificar el significado de la estructura simple, como sucede con el procedimiento de yuxtaposición: Yo tomo café café y de coordinación: Dale que dale. 


\section{Variedad léxico-fraseológica en el discurso periodístico}

Las UFs son combinaciones léxico-sintácticas con un significado unitario que adquiere sentido en la actualización discursiva. Dentro de ellas se incluyen los compuestos sintagmáticos y las locuciones, pero no las colocaciones y construcciones con verbos de apoyo, como manifiestan Bosque (2001, pp. 20-21) y García-Page (2008, p. 12), quienes niegan el carácter fraseológico, aunque tengan un rasgo de las locuciones: la de establecer equivalencia con palabras, como sucede en (2) Las redes sociales se hacen eco del acuerdo en Cataluña (La Razón, 9/1/16).

En el ejemplo 2, la expresión fraseológica verbal, constituida por Vtr.+CD, equivale a "publican o hablan". A pesar de todo, tanto las locuciones como las colocaciones pueden incluirse entre las UFs fijas e idiomáticas, como las locuciones, y las que permiten variaciones, como las colocaciones. No obstante, Ruiz Gurillo (1997a, p. 87) reconoce que "las colocaciones son combinaciones sintagmáticas que no pueden llamarse fijas, pero tampoco son asociaciones libres". Habría que hablar más bien de relaciones graduales entre las combinaciones libres, las colocaciones, los compuestos sintagmáticos, las locuciones y los enunciados fraseológicos.

Para Corpas (2003, p. 131), las UFs se caracterizan por la unidad dada entre sus componentes, tanto para el establecimiento de equivalencias como para iniciar un proceso de desautomatización, en cuanto a que se trata de una propiedad que se atribuye a las UFs. Habla de tres tipos de unidades fraseológicas: las locuciones, las colocaciones y los enunciados fraseológicos libres. Las locuciones no constituyen enunciados completos, sino que, más bien, funcionan como elementos oracionales, dotados de inalterabilidad, y, como dice Koike (2001, p. 31), "se caracterizan por expresar su sentido idiomático en el marco de una estructura fijada". Muchas de las locuciones responden a combinaciones fijas verbales, algunas de la cuales se construyen mediante el esquema $\mathrm{V}+\mathrm{SN}$, como puede verse en numerosos usos del tipo: (3) Amancio Ortega cierra la compra de otro edificio histórico en Londres (El País, 18/1/16).
Como se puede comprobar, en el ejemplo 3, el predicado verbal aparece expresado de forma analítica "V+SN (CD)" en lugar de la forma sintética representada solo por el $\mathrm{V}$ "compra".

Las colocaciones, como explica Zuluaga (2002), son combinaciones de dos o más lexemas en relación hipotáctica fijadas por el uso social. Coseriu (1986) las llama "solidaridades léxicas" y Bosque (2001) considera que no pertenecen a la fraseología, sino a la "interfaz léxico-sintáctica”. De todos modos, las colocaciones pueden definirse como las unidades fraseológicas constituidas por dos componentes no idiomáticos: la base (o colocado) y la extensión colocativa (o colocativo). Dentro de ellas, se insertan las construcciones con verbo soporte. Es decir, son unidades fraseológicas formadas por dos unidades léxicas en relación sintáctica que por su fijación presentan restricciones de combinación establecidas por el uso con base semántica, como en (4) El tiempo dirá si el nuevo sistema es capaz de cumplir con las expectativas o si estamos condenados a dar un paso atrás. Estos son los riesgos de la nueva política (El País, 29/12/15).

El verbo "dar" en el ejemplo 4 constituye una unidad formada por Vtr.+CD, por lo que exige una complementación por tratarse de un verbo de predicación incompleta, y, a su vez, es bivalente al necesitar de dos argumentos relacionados con la proyección del sujeto hacia el objeto. Aunque aparentemente es una expresión formalizada, en realidad se puede calificar de colocación puesto que admite variantes como "dar marcha atrás".

Y, por último, a diferencia de las locuciones y las colocaciones, los enunciados fraseológicos constituyen para Zuluaga (1980, p. 129) por sí mismos enunciados completos o bien "secuencias autónomas de habla, cuya enunciación se lleva a cabo en unidades de entonación distintas". Por su parte, Corpas (1996, pp. 135-136) distingue dos tipos de enunciados fraseológicos: las paremias (refranes, eslóganes, consignas y citas) y las fórmulas rutinarias, que son enunciados prefabricados en determinadas situaciones comunicativas (saludos, despedidas, etc.), como en (5a) Un pirata como Dios manda (referido a la ilustración que José $\mathrm{M}^{\mathrm{a}}$ Gallego hace de La isla del tesoro, El Mundo, 29/4/16). 
El enunciado fraseológico del ejemplo $5^{\mathrm{a}}$, que viene dado a través de una oración atributiva "Vcop. (elidido)+ construcción modal", constituye una expresión fraseológica popular adjunta al sujeto y, al omitirse la $3^{\text {a }}$ persona del verbo "es", adquiere un carácter enfático. Algo similar sucede en b) Los hijos de Conde en el ojo del huracán por ayudarle (El País, 12/4/16).

Así se constata, en el ejemplo 5b, que se trata de un enunciado fraseológico en el que se elide la $3^{\text {a }}$ persona de plural del verbo "están" conformando una expresión nominalizada para indicar que se trata de algo problemático o tormento por asociación con el núcleo de un huracán o ciclón.

Al respecto, Ruiz Gurillo (1998, p. 63) puntualiza que, en general, las UFs están integradas por el centro, del que están dotadas las locuciones, y la periferia, representada por unidades que superan esas estructuras, entre las que se pueden encontrar refranes o expresiones figuradas. Pero entre ambas hay una frontera borrosa donde se combinan palabras formando sintagmas u oraciones, es decir, frases proverbiales, que unas veces estarán cerca de locuciones y en otras de los refranes.

\section{El componente léxico-fraseológico verbal en el discurso periodístico}

\subsection{El grado de formalización del componente fraseológico en el discurso periodístico}

Para explicar el grado de formalización del léxico fraseológico, hay que recurrir no solo a la fraseología y la paremiología, sino también a la lexicología, la gramática y la pragmática. Así en la configuración del predicado, Harris (1976, p. 26) propone la estructura formada por "predicado (operador) + argumentos", donde los operadores responden a expresiones incompletas semánticamente, mientras que los argumentos son palabras que representan entidades, al igual que establece el funcionalista Tesnière (1966, pp. 238-26o), aunque este recurre a la terminología de actante y valencia. Las restricciones principalmente suelen ser de carácter sintáctico-semántico, teniendo en cuenta que los predicados no se conforman solo por verbos, sino también por sustantivos, adjetivos o sintagmas preposicionales, aunque, como dice Subirats (2001, pp. 200-231), en español apenas se ha estudiado la potencialidad argumental del sustantivo y adjetivo. Más aún, al referirse a la composición de la cláusula, Di Tullio (1997, pp. 83 y 89) considera que toda cláusula contiene una estructura predicativa y uno o más argumentos ${ }^{10}$, el sujeto como externo y los complementos como internos. Estos últimos son los que contribuyen a la producción de unidades fraseológicas, como en (6a) Hay que coger el toro por los cuernos ( $E l$ País, 22/02/1997 y El Periódico, 11/04/2008).

El ejemplo 6a responde a una unidad fraseológica unitaria, formada por $\mathrm{V}+\mathrm{CD}$, que se utiliza cuando se hace frente a una situación difícil o se afronta un problema con determinación. Amando de Miguel, en el artículo "Frases hechas y por hacer" (Libertad Digital, 12/o9/2011), explica que esta expresión tiene su origen en unas fiestas con toros del mundo romano aludiendo al mito de Mitra, dios de la antigua Persia que luego pasa a Grecia, Creta y Roma mostrándose como un dios invicto al hundir su daga en el cuello de un toro. Precisamente, el juego de los toros consistía en que el hombre se oponía al "toro" por ser un animal muy resistente. Y también lo vemos en b) Se armó la marimorena en la salida y, a partir de ahí, lo único que quedó claro es que Juan Pablo Montoya sería el ganador (El País, 4/o8/2003).

Se ve cómo en el ejemplo 6b aparece una expresión fraseológica unitaria, constituida por $\mathrm{V}+\mathrm{CD}$, empleada para describir las discusiones o broncas que se producen entre dos o más personas. Es equivalente en español a "trifulca o guirigay". Su origen se remonta a finales del s. XVI en Madrid, donde había una taberna en la Calle Cava Baja, regentada por el matrimonio Alonso de Zayas y María Morena. Ambos se vieron involucrados en un proceso judicial como consecuencia de la trifulca que se produjo en la taberna al negarse a servir su mejor vino a unos soldados que lo pidieron, lo que generó un altercado que pasó de boca en boca con la expresión popular "se armó la Mari morena”.

10 Los argumentos son expresiones referenciales que permiten identificar entidades del mundo extralingüístico. 
Asimismo, al explicar el funcionamiento del CD, Di Tullio (1997, p. 106) presenta una retahíla de expresiones como "dar asco, darse un baño, a la fuga, echar una mirada, tomar nota, prestar atención”, que están formadas por un "verbo soporte", que carece de significado léxico, pero sirve de apoyo a la complementación formando una unidad de sentido integrado o un predicado semántico unitario. En estos casos, toda la construcción funciona como una unidad léxica compleja. En esta línea, Ruiz Gurillo (1997a, pp. 110-114) explica que los sintagmas verbales fraseológicos son unidades fraseológicas que también ocupan diferentes lugares en la escala, que van del centro a la periferia. Hay, pues, varios tipos de locuciones verbales que responden a sintagmas verbales fraseológicos integrados por V+SN o V+ SPrep.

De manera general, se considera la locución verbal dotada de fijación e idiomaticidad, características de las que carecen las colocaciones. Así habría que considerar la locución verbal como una expresión fraseológica formalizada, mientras la colocación sería un procedimiento de construcción de expresiones que están en fase de formalización por lo que admiten variaciones. Según esto, son dos las formas en que pueden presentarse las unidades fraseológicas: unas manifiestan una gran cohesión entre sus formantes, donde el componente verbal funciona como verbo soporte ${ }^{11}$, en expresiones o locuciones verbales formalizadas y enunciados fraseológicos caracterizados por su fijeza e idiomaticidad, como se observa en (7) Un año más, Judas se toma las de Villadiego (El Mundo 25/3/16).

La construcción del ejemplo 7 se corresponde con una unidad fraseológica unitaria caracterizada por su fijeza e idiomaticidad con el significado de "huir o escapar de un sitio con rapidez”. Eso sí, presenta una anomalía estructural, puesto que aparece una elipsis nominal encabezada por el plural del determinante femenino "las" acompañado de un complemento determinativo indicando la referencia de lugar "de Villadiego". Originalmente es una expresión tradicional castellana del s. IX que elide “calças", referida por $1^{\text {a }}$ vez en La Celestina a "las calças de Villadiego" (Burgos). No obstante, hay versiones que la sitúan en el primer tercio del s. XIII, a raíz de la promulgación de un decreto del rey Fernando III 'El Santo' que prohibía perseguir a los judíos en el pueblo de Villadiego (Burgos), por lo que, cuando se sentían amenazados "tomaban las de Villadiego", lugar en que estaban a salvo o servía de refugio.

Otras expresiones fraseológicas, como las colocaciones, no han alcanzado el grado de formalización idiomático, como se comprueba en (8) Un pueblo de Huesca pone contra las cuerdas a la Generalitat de Cataluña ( $A B C, 18 / 1 / 16)$.

El predicado del ejemplo 8 formado por V+SPrep. constituye una unidad fraseológica con sentido figurado equivalente a "cercar o acorralar", aunque adquiere variantes como "poner entre la espada y la pared", "poner al límite", "poner al pie de los caballos", etc., por lo que se corresponde con una colocación. Así pues, las unidades fraseológicas desempeñan diferentes funciones dentro del discurso: unas son inherentes, según Zuluaga (1997, pp. 632-638), entre las que se incluyen la función fraseológica, relacionada con la economía de la expresión lingüística; la connotativa, que proporciona información adicional mediante la evocación o asociaciones significativas; la icónica, a modo de imagen o impresión concreta; y la lúdico-poética mediante el ritmo, la aliteración, la tautología, la expresión coloquial metaforizada e hiperbólica, etc. para llamar la atención, como en (9) (Referido al alcalde de Cádiz) «A ver si algún día estos políticos dejan de tirarse los trastos a la cabeza y se centran en ayudar a los ciudadanos. Les damos igual. Nos llegaron a cortar la luz, tuvimos que tirar la poca comida que teníamos en el congelador. Pero eso les da igual. Les da igual que te quedes en la calle. Sólo les interesa el poder, llenarse los bolsillos», añade. "Estamos desesperados, queremos una vida normal. Qué impotencia sentimos... Si pedimos ayuda es porque la necesitamos, joder, no disfruto yendo a hablar con la asistente social», suspira Tamara (La Razón, 3/4/16).

\footnotetext{
11 Muchas de estas construcciones están formadas por un componente verbal que actúan de verbo soporte por haber sufrido un proceso de desemantización. Puede decirse que, según el grado de lexicalización adquirida, la locución puede ser totalmente idiomática, semiidiomática, escasamente idiomática o variacional (con variantes).
} 
En el ejemplo 9 se pone de manifiesto la constante productividad fraseológica popular del tipo "tirarse los trastos a la cabeza" por "enfrentarse o insultarse"; "darles igual" por "pasar"; y "llenarse los bolsillos" por "enriquecerse". A su vez, hay otras expresiones no inherentes, como el comentario, la explicación, la descripción, la argumentación, la exhortación, la enseñanza, la caracterización de personajes, etc. en el contexto discursivo.

A todas ellas se añaden las funciones semánticoestilísticas, que contribuyen a que la expresión fraseológica adquiera el valor pragmático deseado por parte del locutor, como: (10) En Cataluña no es oro todo lo que reluce (El Confidencial, 23/11/15).

En el ejemplo 10, el componente semántico-estilístico de la metáfora muestra que la representación política trata de dar una imagen pública que no se corresponde con la realidad que en parte ocultan. Se trata de una unidad fraseológica expresada de forma negativa para mostrar que las apariencias engañan y advertir que no hay que dejarse llevar de lo que se percibe a primera vista.

\subsection{El verbo, núcleo de la unidad fraseológica verbal}

El verbo contiene realidades sintácticas muy diferentes, que permiten distinguir dos grandes grupos de verbossoporte: los de carácter general -dar, echar, hacer, poner, tomar, tener-, y los de uso más restringido a sustantivos con variantes de carácter estilístico (coloquial, culto, literario) y aspectual (incoativo, progresivo, intensivo o terminativo). Así cabe decir que algunos verbos

efectúan una referencia léxica tan general que su contenido, de puro abstracto, parece como vacío de referencia a una realidad inequívoca si no va concretado un término adyacente: hacer, dar, tener». Además, dice que «no hay límite entre unos y otros tipos, sino una gradación [...] que "no es gramatical, sino léxica” (Alarcos, 1972, p. 113).
A ello habría que añadir que la transitividad e intransitividad no dependen tanto de la significación categorial ni de la significación léxica, sino de los usos, es decir, de las interpretaciones conceptuales que los hablantes atribuyen a los verbos. Hay verbos que léxicamente contienen un significado que selecciona los complementos que necesita por su proximidad significativa, por asociación o transposición semántica, que permiten la recuperación del verbo: (11a) Una reunión de mucho humo, mucho ruido y pocas nueces (La Razón, 3/3/16).

En el ejemplo 11a nos encontramos con una expresión nominal en serie coordinada que juega con el contraste léxico "mucho-pocas" y la elisión de las formas verbales "fue" y "tuvo o hubo". Es una alusión metafórica que se aplica a casos en que se hacen alardes de algo pero con poco fondo o resulta superficial y pobre. Parece que surgió a finales del s. XVI como estrategia del capitán Hernán Tello en la toma de Amiens durante las guerras de Flandes, quien arrojó unas canastas llenas de nueces a la plaza enemiga lo que provocó mucho ruido y la distracción de los vigilantes.

Y hay formalizaciones constituidas por $\mathrm{V}+$ complementos preposicionales, como en b) Toni Cantó vuelve a liarla en Twitter (El Plural, 25/2/16).

En el ejemplo 11b, el predicado responde a una perífrasis verbal reiterativa que adquiere un sentido metafórica equivalente a "vuelve a cometer otro error". No obstante, el verbo "liar+pronombre personal" (liarlo, liarla) se utiliza frecuentemente con matiz peyorativo con significado de "confusión, descontrol, juerga, follón, escándalo, etc." y con frecuencia se le añade el adjetivo en femenino "parda" que da lugar a la locución "liarla parda".

Otros verbos transitivos presentan una significación tan extensa que necesitan concretar su significado en expresiones del tipo Tiene hambre, miedo, dinero, paz, fuerzas, frío, razón, guasa / Hace frío, mal tiempo, viento, etc. Puede decirse que las locuciones verbales, constituidas por verbo como núcleo sintáctico y uno o varios complementos integrantes del predicado, forman parte de las expresiones fraseológicas verbales. 
En cualquier caso, para la NGLE (2009, p. II, 2649-54), las locuciones verbales se forman sobre todo con verbos transitivos cuyos complementos llegan a lexicalizarse, pero suelen presentar un "diverso grado de transparencia", como: (12a) El PSOE tira la toalla y asume las elecciones $(L D, 8 / 4 / 16)$.

En la oración del ejemplo 12a hay dos predicados coordinados: el $1^{0}$ "tira la toalla" responde a una locución verbal equivalente a "renuncia" por el proceso de metaforización logrado, a diferencia del $2^{\circ}$ predicado "asume las elecciones" en el que sus componentes mantienen su independencia significativa.

A pesar de lo explicado en 12a, no está claro este modo de producirse la locución verbal en todos los casos, puesto que hay verbos que han perdido parte de su significado léxico en favor de los complementos sin otro verbo que pueda suplirlo, como en b) Las nuevas Cortes dan pie a que las opiniones de los votantes sean difíciles de reconciliar (El País, 29/12/15).

El predicado en el ejemplo 12b está constituido por un verbo "dar" que actúa como soporte por haber perdido parte de su significado y responde a una locución verbal formada por "V+SN" al configurarse sintácticamente por metaforización equivalente a "dan lugar", pero no cabe sustituirla por una sola palabra.

No obstante, además de los transitivos, hay varios verbos intransitivos que forman expresiones fraseológicas verbales por su propio carácter, como en (13a) La energía solar sale a flote en Reino Unido (El Mundo, 3/4/16).

El predicado del ejemplo 13a se corresponde con una expresión formalizada que está constituida por V+SPrep. para indicar que se sale airoso ante alguna dificultad por asociación a las embarcaciones en el mar.

Y también por la conversión de verbos transitivos en intransitivos, como b) Los 'espías' de Madrid quieren tirar de la manta y testificar en la Asamblea (El Confidencial, 9/1/16).
La construcción predicativa del ejemplo 13b responde a expresión fraseológica integrada por $\mathrm{V}+\mathrm{SPrep}$ que se utiliza cuando se destapa algún asunto sucio o vergonzoso que estaba oculto y que podría comprometer a alguien. Parece ser que tiene su origen en siglos XVI y XVII en relación con los judíos conversos, puesto que en algunas zonas de Navarra se llamaban "mantas" a grandes lienzos que colgaban de las paredes de las iglesias donde aparecían los nombres y apellidos de las familias descendientes de judíos que se habían convertido al cristianismo.

A ellos se unen los verbos pronominales considerados como eventuales, principalmente "darse", como en c) (Refiriéndose al cantante Manolo Tena) [...] cuando comenzó a cosechar sus primeros éxitos, se dio de bruces con Hacienda (El Confidencial, 6/5/16).

El predicado del ejemplo 13c constituye una expresión verbal usada coloquialmente para indicar que "se golpeó o se cayó"; en este caso, viene a significar que "chocó o tuvo que vérselas con Hacienda”. En este tipo de expresiones se observa la presencia de un verbo que actúa de soporte de esta y de otras muchas unidades fraseológicas verbales en forma de colocaciones, puesto que sus componentes admiten modificaciones, como "darse de narices, darse a la fuga, salir a flote o adelante", "tirar de la manta o del hilo" y "se dio de bruces o con los dientes en el suelo".

\subsection{Configuración sintáctica del léxico- fraseológico}

Normalmente, al explicar las UFs verbales hay que fijarse en las de carácter transitivo, puesto que pueden hacer que la acción recaiga sobre un objeto exterior a modo de CD. Para Casares (1992, p. 178), los diversos tipos de locuciones verbales muestran normalmente estos aspectos:

- una oración predicativa transitiva, como en (14a) El golpe de mano de P. Iglesias desata el miedo a la purga de disidentes (La Razón, 17/3/16). 
El ejemplo 14a contiene una expresión constituida por $\mathrm{V}$ $+\mathrm{SN}$, que equivale figuradamente a "atemoriza" por el proceso de metaforización.

- una predicativa intransitiva, como en b) Carmena vuelve a la carga: quiere implantar la tasa turística en Madrid ( $L D, 8 / 3 / 16)$.

El predicado de 14 b constituye una expresión formada por V + Sprep., equivalente a "insistir con empeño".

- y una construcción atributiva con los verbos "ser y estar", como en c) Este pacto de legislatura es una tomadura de pelo (La Razón, 24/2/16), constituida por VAtr. + SN + Sprep.

En el ejemplo 14c la estructura del predicado se corresponde con una expresión fraseológica formada por Vatrib.+SN con el significado figuradamente de "broma, engaño o falsedad".

De cualquier forma, las funciones sintácticas no se corresponden siempre con el régimen del verbo de la locución (o el verbo a que equivale la UF), como se comprueba en (15a) El expresidente popular de Murcia pide a Rajoy que dé un paso atrás (El País, 9/3/16).

Así, en el ejemplo 15a, el predicado se corresponde con una expresión fraseológica en forma de colocación, formada por el verbo transitivo "dar + SN", en lugar del intransitivo sintético que representa su equivalente léxico-semántico "se retire", al admitir modificaciones del tipo "dar marcha atrás”.

Eso sí, en muchos casos los verbos admiten variaciones temporales, personales y modales, como en b) Parece que le dan ya por muerto (LD. 3012/15) / [...] que a Julio Cortázar mismo, es decir a su literatura, se lo suela dar por muerto con sospechosa recurrencia (El País, 10/05/2009).

En los dos ejemplos de 15b, los predicados subrayados, formados por $\mathrm{V}+$ Sprep., constituyen unidades fraseológicas semejantes en las que se anticipa la derrota cuando se prevé que no se va a alcanzar lo que uno se propone.
Ambas son claramente colocaciones, al admitir variantes del tipo "le dan (ya) por desaparecido", con la diferencia de que en el primero se intercala el puntualizador temporal "ya" entre verbo y sintagma preposicional. Y es muy frecuente esta construcción fraseológica con el verbo "dar", como "dar por hecho": c) Le dio un cheque en blanco porque entendía era mejor ( $L D, 30 / 12 / 15)$.

En el ejemplo de 15c, el predicado verbal adquiere valor de unidad fraseológica verbal, constituida por $\mathrm{V}+\mathrm{SN}$ (CD)+SPrep, por metaforización para señalar que se da a otra persona un poder de decisión ilimitado sobre algún asunto.

Asimismo, según la estructura interna de las unidades fraseológicas, Zuluaga (1980, p. 136) habla de diferentes grados de fijación lingüística:

- Fijas no idiomáticas, como en (16a) Dicho y hecho

En el ejemplo 16a, se presenta una expresión unitaria en que se unen coordinadamente el participio de "decir" y "hacer" para indicar que cumple de inmediato con su palabra o que se hace algo inmediatamente de pensarlo y decirlo. El juego de estos dos participios ha dado lugar al refrán tradicional "Del dicho al hecho hay mucho trecho" con el significado de que hay mucha distancia entre lo que se dice y lo que se hace.

- Semiidiomáticas, como b) Tira y afloja

El ejemplo 16b constituye una locución nominal con dos elementos nominales unidos por coordinación, que mantienen un vínculo lógico por oposición, referido a que en una negociación se cede y se concede.

- Idiomáticas mixtas, como c) Piedra de toque

En el ejemplo 16c, se presenta una expresión fraseológica nominal de subordinación constituida por "N+Sprep." que se utiliza para señalar el valor preciso de una cosa por asociación semántica con un tipo de piedra dura de color oscuro con mezcla de cuarzo amorfo y otros minerales que sirve para conocer el valor de una alhaja. 
- Mixtas con elementos únicos, como en d) Tener gracia

El ejemplo de 16d representa un predicado verbal formado por Vtr.+CD, que constituye, según el DLE, una locución verbal coloquial para señalar una situación agradable o divertida, pero también se utiliza con sentido irónico, es decir, como expresión hecha con tono desenfadado para manifestar algún desagrado.

- Con alguna anomalía estructural, como en e) $A$ ojos vistas y A pie juntillas

La expresión nominal del ejemplo 16e es una locución adverbial que no responde a la norma gramatical de concordancia de género equivalente al adverbio "visiblemente"; y A pie juntillas: es también una locución adverbial que tampoco se ajusta a la norma gramatical de concordancia ni de género ni número, pero se utiliza para indicar "con los pies juntos".

- Con elementos metalingüísticos: f) Quien vale vale y el nombre ni quita ni pone

En el ejemplo $16 \mathrm{f}$ se nos muestra una expresión tautológica, formada por "una parte de subordinación sustantiva (o adjetiva libre) de sujeto "Quien vale" y otra, que es la principal con el verbo "vale", para hacer resaltar que una persona es competente en un asunto. Y El nombre ni quita ni pone, expresión en forma de enunciado fraseológico, constituido por dos elementos verbales de significado opuesto, pero coordinados mediante el indicador negativo "ni" que contribuye a la neutralización de los términos antónimos. Por eso, se utiliza para indicar que una persona no se cualifica simplemente por el nombre.

- Idiomáticas con estructura regular: g) Tocar las narices

En el ejemplo 16g, la oración está formada por Vtr.+CD y constituye una expresión fraseológica en forma de colocación, puesto que admite variantes del tipo "tocar las pelotas, la moral, etc.”. Se utiliza normalmente con sentido metafórico para indicar que la actitud de una persona molesta, por lo que equivale a "molestar o fastidiar".
En el corpus del discurso periodístico analizado hay un amplio número de expresiones fraseológicas verbales constituidas por componentes variados, aunque domina la estructura constituida por $\mathrm{V}+\mathrm{SN}$, por lo que puede afirmarse que se trata de un procedimiento gramatical altamente productivo. Algunas de estas expresiones se pueden considerar como locuciones, pero otras responden a colocaciones. La diferencia, como se ha venido diciendo, se basa en el grado adquirido de formalización y fijeza y en la capacidad de admitir o no modificaciones, como en el caso de las colocaciones.

En cualquier caso, los componentes de las expresiones fraseológicas que conforman una estructura fija no tienen valor opositivo, a juicio de Zuluaga (1980, p. 99), consideradas "estructuras pluriverbales complejas" que funcionan como un todo unitario, como (17a) Ni Bale ni Cristiano dan pie con bola, pero el que se lleva el palo de Benítez es James (El Confidencial 9/11/2015).

El ejemplo 17a presenta un predicado formado por $\mathrm{Vtr},+\mathrm{CD}+$ Complemento determinativo y constituye una expresión fraseológica verbal unitaria en la que no cabe modificar morfológicamente ningún componente del tipo *dar pies con bola, puesto que se producirían anomalías gramaticales no reconocidas por los hablantes.

Por esta razón, puede afirmarse que son estructuras que no constituyen esquemas sintácticos productivos al no admitir modificaciones. No obstante, cabe decir que en el discurso periodístico se utiliza una amplia variedad de esquemas fraseológicos, que constituyen estructuras regulares dentro de los mismos procedimientos léxicosintácticos. Muchos de ellos responden a sintagmas verbales fraseológicos, entre los que se incluyen las colocaciones, cuyos componentes presentan una alta coaparición por razones de solidaridad léxica, en términos de Coseriu (1986), y las unidades sintagmáticas verbales, que, a juicio de Ruiz Gurillo (1997a, pp. 110-112), constituyen conglomerados donde el componente verbal ha perdido sus valores léxicos y soporta los morfológicos del conjunto. Esto le permite hablar de sintagmas verbales o esquemas fraseológicos con diferente grado de formalización mediante el procedimiento de metaforización y de asociación semántica. 
Así se forman estructuras V+SN o V + Sprep. y locuciones con alto grado de

- fijación e idiomaticidad, como en b) Dorar la píldora

En el ejemplo 17b se muestra una construcción verbal formada por Vtr. $+\mathrm{CD}$, que da lugar a una unidad fraseológica fija e idiomática que se utiliza como atenuación al efecto negativo de una mala noticia en una persona y también cuando se pretende obtener algún favor de alguien. Tiene su origen en la preparación manual de los remedios farmacéuticos de los boticarios en forma de píldora que, para eliminar el sabor amargo, lo enmascaraban con una sustancia dulce.

- semiidiomáticas: c) Echar raíces

El ejemplo de 17c, formado por Vtr.+CD, constituye, según el DLE, una locución verbal con el significado de establecerse de modo permanente en un lugar o mantenerse en un trabajo o arraigarse. De cualquier forma el verbo "echar" se convierte en un verbo soporte para la configuración de expresiones similares del tipo "echar cuentas" por "calcular", "echar(le) narices" o "echar valor”.

- poco idiomáticas: d) Partir el pecho

El ejemplo de 17d es un predicado verbal formado por Vtr.+CD constituye una expresión verbal de carácter hiperbólico utilizada para defenderse de algo o defender a alguien sin ninguna duda. Puede equivaler a otras expresiones del tipo "dar la cara por alguien" o "ponerse en su lugar".

- mixtas: e) Vivir del cuento

La construcción del ejemplo 17e está formada por Vintr.+Sprep y responde a una expresión verbal con el significado de "aprovecharse de los demás" o "vivir sin trabajar" por el procedimiento de asociación con la ficción del cuento donde concurren apariencias y engaños.
- meramente fijas: f) Reír las gracias

La construcción del ejemplo 17f, formada por Vtr.+CD, es una expresión verbal usada metafóricamente para alabar o aplaudir alguna cosa dicha por una persona para adularla con el fin de conseguir algo de ella equivalente a "hacer la pelota", aunque no tenga humor ni sea graciosa. En cambio, la expresión semejante de "dar las gracias" forma parte de la cortesía en todas las culturas.

- locuciones con variantes: g) Importar un bledo

El ejemplo 17g es una construcción constituida por Vtr.+CD que responde a una expresión verbal formalizada para expresar negación por asociación con una planta "el bledo" que tiene tallos comestibles pero nada apreciados para indicar lo poco que importan las cosas o para negar. Convienen con ella otras muchas expresiones negativas: "importar un pepino, un pimiento, un higo, un comino, un carajo", etc.

- unidades sintagmáticas verbales y otras colocaciones: h) Tomar nota

El ejemplo de 17h es una construcción verbal formada por Vtr.+CD con el significado literal de "apuntar algo que hay que recordar por escrito", pero también es una expresión hecha para fijar o grabar en la memoria una idea o algo que ha llamado la atención, como en i) Cantar las cuarenta.

El ejemplo de 17i es una construcción verbal formada por Vtr.+CD que se utiliza en el juego de naipes, como el tute, para indicar que "a quien canta las cuarenta" se le otorgan cuarenta puntos para añadir al resto de puntos obtenidos al final de cada juego. A su vez, es una expresión verbal de carácter metafórico que se emplea para "regañar o abroncar a alguien por algo que ha hecho o dicho y ha molestado o causado algún perjuicio.

A pesar de esta variedad terminológica, no está clara la diferenciación existente entre los tipos de expresiones fraseológicas referidas atendiendo al grado de fijación de sus componentes. Por ello, conviene, en principio, conocer la estructura con que se presentan las unidades 
fraseológicas en el discurso y, a continuación, explicar el grado de formalización adquirido en función de la integración de los componentes y de las posibilidades de modificación. Esto nos permitirá saber si son esquemas fraseológicos pertenecientes a locuciones y enunciados fraseológicos o se corresponden con colocaciones. Entre los esquemas fraseológicos más frecuentes utilizados en el discurso periodístico, se puede hablar de los integrados por:

- V + SN: (18) El experimento digital que puede poner patas arriba las votaciones en Madrid ( $L D$, 18/12/15).

La construcción predicativa del ejemplo 18 es una expresión fraseológica verbal transitiva "V (poner)+Complemento modal (patas arriba)+CD (las votaciones)" con sentido metafórico para referirse a algo caótico o desordenado. En este caso, se configura como una locución verbal donde los componentes se integran proporcionando un significado equivalente a "cambiar totalmente" el sistema de votaciones, aunque la expresión habitual lleva como CD el indefinido "todo": "poner todo patas arriba".

- VCop. + SN o locución nominal (o SPrep.): (19a) Fue una lástima, sin embargo, que apenas reservara un par de minutos para hablar sobre temas tan importantes como son el empleo, la sanidad o la educación (El País, 29/12/15).

La construcción predicativa del ejemplo 19a, formada por "Vatrib.(ser)+SN", responde a una estructura atributiva empleada para mostrar una sensación interna con el significado de "lamentación", a la vez que lleva implícito un tono enfático. Con frecuencia esta expresión va reforzada con el adjetivo "verdadero/a": "fue una verdadera lástima", con "Vatrib.+SN" muy productiva en español del tipo "es pan comido” para señalar la facilidad de hacer algo. Y b) Un suicida en Bruselas estaba en busca y captura por el 13 N de París (La Razón, 24/3/16).

En el ejemplo 19b, la estructura es también atributiva, constituida por "Vatrib.(estar)+SN", que da lugar a una expresión nominal formalizada vinculada al discurso jurídico.
Ambas estructuras predicativas, a y b, sirven para opinar e informar. No obstante, son diferentes: en 19a se presenta una estructura atributiva Vatr. + SN, gramaticalmente concertada, para expresar lamento en forma de enunciado fraseológico; y en b, la construcción se forma con Vatr. + locución nominal prepositiva y viene a equivaler a una expresión sintagmática verbal del tipo "estar perseguido o en persecución”, con alto grado de formalización.

- V + SPreposicional: (20a) El guardia civil que acribilló a un conductor: Quiso darse a la fuga (ABC 26/4/16) y b) Los socios del Madrid están hasta el gorro (La Sexta, Pedrerol 7/4/16).

En ambos ejemplos, 20a y b, los predicados subrayados son expresiones sintagmáticas verbales, producto de la metaforización de sus componentes para expresar en a) que "quiso escaparse, largarse, huir", pero se corresponde con una colocación al admitir modificaciones del tipo "darse el bote", aunque en español hay muchas equivalencias sintagmáticas: "poner pies en polvorosa, salir pitando, poner tierra por medio", etc.; y en b) aparece un Vatr. + locución nominal prepositiva para expresar hartazgo por algo, aunque puede presentar variantes equivalentes del tipo: "estar harto, estar hasta la coronilla, el copete, las narices, etc.”, por lo que se corresponde con una colocación.

- $\mathrm{V}+$ pronombre $+\mathrm{SN}$ : (21) (Dice el piloto Joan Barrera) "Se ha ido todo al traste" ( $A B C$, 18/1/2016).

El ejemplo 21 constituye una expresión verbal semifija de la que se infiere que "está decepcionado" o "ha fracasado", pero puede considerarse como una colocación en cuanto a que pueden modificarse algunos de sus componentes, por lo que puede decirse: "Se ha ido al carajo o todo al garete”. Esta última expresión, surgida en el ambiente marinero, es de uso frecuente con el significado de "irse a la deriva” cuando la embarcación perdía el control. También se emplea esta expresión en situaciones de enfado y se sustituye el verbo "irse" por "mandar", como "mandar a alguien a la porra, a hacer puñetas, lejos, etc". 
- V + Adjetivo: (22) El Rey estuvo ejemplarizante a la hora de argumentar por qué se debe respetar la unidad de España y nuestro orden constitucional (La Razón, 24/3/16).

El ejemplo 22 recoge una expresión en la que se interpreta y califica positivamente la intervención del sujeto enunciador "el Rey". Aunque no se considera una expresión fraseológica plena, puede equivaler a una colocación formada por una construcción sintáctica frecuente de "Vatr. + adjetivo" para dotar al significado en su conjunto de carácter ponderativo, procedimiento habitual en el discurso periodístico. A veces, se metaforiza en casos como "estuvo sembrado" (habló bien).

- V + proposición: (23) No se despidió de nadie. Rafa Benítez está que echa humo (Marca, 6/1/16).

La construcción predicativa de 23 constituye una expresión sintagmática verbal metafórica de carácter enfático, puesto que encierra una estructura comparativa al elidirse el adverbio comparativo "tan" y el adjetivo "enfadado" en relación con el $2^{\circ}$ término de comparación "que", por lo que responde a la construcción completa "R. Benítez está (tan enfadado) que echa humo", para manifestar de forma enfática e hiperbólica "su enorme enfado" por su destitución como entrenador del R. Madrid. El DLE la considera "locución verbal" coloquial, que puede equivaler a "está que muerde".

- V + Adverbio o locución: (24) Los policías echan de menos a sus antidisturbios tras dos días de pesadilla (El Confidencial, 7/16).

La expresión del ejemplo 24 se corresponde con una locución verbal equivalente a "añorar o advertir la falta". A pesar de estar consolidada esta expresión, caben variantes con significado semejante del tipo: "echar en falta" con el significado, recogido en el Diccionario panhispánico de dudas (2005) de "notar la falta de alguien o algo".

- Enunciados, caracterizados por constituir unidades independientes (UFs): (25) "Como Rivera ya ha dicho que vale y además ni pincha ni corta, presiona a Pedrito" (LD, 30 /12/15).
En el ejemplo 25 aparecen dos expresiones verbales de carácter unitario en forma de enunciados fraseológicos constituidos, respectivamente, por subordinación "ha dicho que vale" con el significado simplificado de "acepta" y por coordinación copulativa negativa de dos verbos asociados semánticamente "ni pincha ni corta" con el significado de "carece de poder de decisión".

Algunas de estas expresiones fraseológicas verbales están relacionadas con locuciones clausales, que, como señala Corpas (1996, pp. 109-110), engloba "locuciones de diversa índole formadas por varios sintagmas, de los cuales al menos uno de ellos es verbal”. En cualquier caso, varias de las expresiones referidas responden a la concepción de locución, en los términos empleados por Casares (1992, p. 170), considerada como "combinación estable de dos o más términos que funciona como elemento oracional y cuyo sentido unitario no se justifica, sin más, como una suma del significado normal de sus componentes". En este caso, las expresiones del tipo 18, 19b, 23 y 24 presentan una estructura verbal de carácter locucional, que tienen funcional y semánticamente carácter unitario, al asociarse sus componentes al núcleo del SV. En cambio, las expresiones 20a, 20b, 21 y 22 responden a colocaciones, en cuanto a que admiten variantes en sus componentes; $y$ las expresiones 19a y 25 se incluirían entre los enunciados fraseológicos, de acuerdo con el criterio de Zuluaga (1980, p. 181), al considerarlos como unidades comunicativas mínimas con sentido propio, es decir, se manifiestan como unidades fraseológicas con un grado de fijación alto para constituir actos de habla por sí solos. Por su parte, García-Page (2001) entiende que las unidades fraseológicas pueden presentar variación léxica, pero lo explica aduciendo al inventario cerrado de elementos, por lo que las considera con mayor fijeza que los sintagmas libres. 


\section{Valor semántico del léxico-fraseológico en el discurso periodístico}

Las UFs suelen contener dos tipos de significado: uno literal, que obedece al significado denotativo de los elementos que las conforman, y otros figurados o traslaticios, que son los que permiten dotarlas de idiomaticidad. Así vemos, por ejemplo, que una expresión puede presentar variaciones dialectales, como en (26) Cortar el rostro y Cortar el bacalao.

Así, el ejemplo 26 está constituido por un predicado con Vtr.+CD, cuyo significado literal es "Cortar a alguien el rostro", pero en el español de Argentina figuradamente se refiere a "No responderle a alguien o no concederle, de manera ostensible, importancia a lo que dice o hace y hacerlo quedar en ridículo frente a los demás". De igual modo, el predicado verbal "cortar el bacalao" significa literalmente separar el bacalao en porciones, pero, como expresión fraseológica verbal, adquiere figuradamente en el español de España un significado metafórico referido a alguien que tiene capacidad de maniobrar en asuntos importantes. El origen de esta expresión procede de la tradición de que quien cortaba el bacalao en las tiendas de ultramarinos era el dueño, quien mandaba y tomaba decisiones, por lo que ha adquirido significado fraseológico por asociación semántica.

Dentro del proceso de lexicalización, la locución es la unidad fraseológica que está más alejada de la unidad "sintagma” y más próxima al de "unidad léxica" por el grado de fijación e idiomaticidad adquirido. En esa línea se sitúan los fraseologismos metafóricos. Para Lakoff y Johnson (2001, p. 41), "La esencia de la metáfora es entender y experimentar un tipo de cosa en términos de otra”. Así, cuando se lee un titular como en (27) Rajoy: "Al gobierno no le temblará el pulso" (ante el desafío independentista de Cataluña (LA SER, 28/10/15).

La construcción predicativa del ejemplo 27 responde a una colocación, al adquirir variantes del tipo "temblar la mano”. Se trata de una expresión fraseológica con sentido metafórico para indicar que el gobierno, con el presidente a la cabeza, actuará con rigor sin ningún complejo sobre un acontecimiento grave (en este caso, la tentativa independentista catalana). Según se constata, el procedimiento metafórico afecta al significado idiomático de toda la expresión fraseológica, por lo que hay una estrecha vinculación entre el pensamiento del hablante y el mecanismo metafórico que lo explica.

Normalmente, en construcciones con Verbo de Apoyo, la caracterización semántica va desde el $\mathrm{SN}$ al Verbo $(\mathrm{V} \leftarrow \mathrm{S})$, lo que permite hablar de "expresión fraseológica integrada" en relación con el contexto. Por eso con todos los verbos señalados se produce un número amplio de colocaciones, como también lo señala Koike (2001, pp. 41-60). Además, los verbos que funcionan de Apoyo convierten a los complementos que los acompañan en componentes léxicosemánticos de referencia temática que contribuyen a la gramaticalización por la linealidad en su disposición sintáctica y por la relación asociativa -estática o dinámicaque se produce entre ellos. Algunos analistas explican este proceso de gramaticalización de expresiones por el carácter neutro de los verbos de apoyo y también lo atribuyen a la presencia de las coordenadas espaciotemporales ligadas al contexto en que intervienen los interlocutores que actúan como universales semánticos de la comunicación. Además de la aportación del verbo soporte en la configuración de las expresiones verbales, es el procedimiento metafórico el que más afecta no solo a los significados figurados de los lexemas simples, sino también al significado idiomático de las expresiones fraseológicas. Si a los procedimientos traslaticios de las expresiones fraseológicos añadimos el significado pragmático que adquieren en cada acto de habla, podemos decir con Corpas (2000, p. 483) que se incrementa la dificultad para la traducción a otras lenguas.

\section{Proyección pragmático-discursiva del léxico-fraseológico en el discurso periodístico}

El aspecto que mejor refleja la coloquialidad en el discurso periodístico está relacionado con el léxico, principalmente el proporcionado por las expresiones fraseológicas verbales, conformadas muchas de ellas, como dice Blanco Escoda (2000, p. 99), por VApoyo que son verbos semánticamente vacíos en cuanto a que conjugan el nombre al que acompañan", por lo que posee 
una gran variedad de uso asociado al contexto. Como apunta Van Dijk (1980, p. 37), en el género periodístico en general y en los titulares en particular se refleja de un modo u otro algún aspecto ideológico, pero también en los artículos de opinión, teniendo en cuenta que lo ideológico está relacionado con aspectos de la política, la religión, la literatura, el arte, la cultura, etc.

Para ello, se recurre a los procedimientos de reproducción discursiva. Ahora bien, hay claramente una diferencia entre el discurso reproducido directo, que establece una semejanza entre la expresión verbal y el resultado lingüístico de la enunciación, y el referido, que no es nada más que una acción expresada verbalmente, de ahí que tengan sentido las palabras de Maldonado (1991, p. 20), al señalar que reproducir supone siempre referir, pero no al contrario. Así se puede ver en:

(28a) “¿Eso significa que hay que poner en cuestión todos los pactos? ¿También el de Compromís en la Comunidad Valenciana?" ( $L D, 30 / 12 / 15)$.

El ejemplo 28a, constituido por "V+Sprep.", responde a discurso directo mediante una expresión verbal equivalente a "cuestionar" y a otras expresiones del tipo "poner en duda". Son, pues, muchas las fórmulas semejantes constituidas con el verbo "poner", como "poner en claro" o "poner en peligro", que María Moliner en su Diccionario de uso del español (Gredos, 2008) las considera totalmente asentadas, pero otras de uso muy actual, como "poner en valor", no están recogidas en su diccionario. En cambio, sí la recogen Manuel Seco y otros en el Diccionario del español actual (Aguilar, 1999), con la indicación de que sigue una pauta de formación semejante a otro tipo de expresiones formalizadas como "poner en claro o poner en cuestión”. La posibilidad de presentar variantes permite calificarlas de colocaciones.

Y el referido en b) Rebelión interna en el INE: un sindicato pone en solfa las prácticas del presidente (El Confidencial, 18/12/15).

En el ejemplo 28b se recurre a una expresión fraseológica verbal formada por $\mathrm{V}+\mathrm{SPrep}$. con el significado de criticar la conducta de alguien en sentido figurado. Equivale a otras expresiones del tipo "poner en tela de juicio", "poner en ridículo", "poner en la picota", etc., por lo que se encuadraría también entre las colocaciones. No obstante, aunque ambas expresiones 28a) y b) están sustentadas por el mismo verbo soporte "poner + SPrep." del que se infiere un sentido de "crítica": en a) se hace mediante un discurso directo, en que el locutor refleja las palabras textuales del enunciador cuya expresión fraseológica puede sustituirse por "cuestionar" y en b) se recurre al discurso referido y la expresión fraseológica se sustituiría por "rechazar".

De todos modos, como se pone de manifiesto en los ejemplos anteriores, todo texto es polifónico, de acuerdo con el pensamiento de Ducrot (1984, p. 205), en cuanto que en él suelen resonar muchas voces de interlocutores que actúan de enunciadores en el texto, por lo que puede decirse que se trata de un componente inherente al discurso. A través del discurso ajeno, en palabras de Nadal (2009, p. 17), se deja traslucir, de manera explícita e implícita, la presencia de una enunciación ajena a la propia. Para Ducrot (1984), todos los enunciados son polifónicos porque el locutor presenta diferentes puntos de vista, atribuidos a los diversos enunciadores o interlocutores que interactúan en el discurso. La interpretación permite descubrir la significación de un hecho o un acontecimiento transmitido por un sujeto enunciador. Se trata de conocer quién habla (locutor), desde dónde habla, de qué habla, en qué momento y a quién habla (intérprete).

Precisamente en el discurso periodístico están presentes la interlocución, las coordenadas espacio-temporales, los elementos lingüísticos y los componentes discursivos para llevar a cabo las operaciones metadiscursivas que afloran en el discurso. A ello contribuye la deixis junto al léxico en general y el fraseológico en particular, al tono y a la intención proyectada, como se ve en (29) Para ellos, terminar con un Gobierno del PP o con una repetición de los comicios solo puede ser una decepción. En los últimos días la cúpula del partido se ha cuidado de poner sobre la mesa otras condiciones de tono más social para recordar a estos votantes que ellos también están por el cambio en el resto de frentes, situando al PSOE dentro del marco de quienes no desean moverse del consenso del régimen ( $E l$ País, 29/12/15). 
Aquí, en el ejemplo 29, el locutor recurre a la deixis para situar el contenido referencial del texto en el contexto espacio-temporal adecuado con todos los enunciadores que entran en el escenario político (gobierno, PP, PSOE, votantes, partido), pero también a expresiones fraseológicas verbales con implicaciones pragmáticas características, como la búsqueda de la transparencia mediante "poner sobre la mesa" por "aclarar"; el deseo de cambio de rumbo en la gobernabilidad mediante "están por el cambio"; y el contraste ideológico mediante "quienes no desean moverse del consenso del régimen". Todo ello contribuye a articular unas partes del discurso con otras identificando cómo se anuncia lo que se pretende decir a continuación (catáfora), cómo se recurre a lo que se ha dicho (anáfora), cómo se enmarcan las pausas y cómo se encadenan las ideas.

En cualquier tipo de discurso, y más concretamente en el periodístico, hay una clara correspondencia entre nociones lingüísticas y cognitivas, al insertarse en él conocimientos, creencias, opiniones y actitudes con todos los prejuicios, como explica Van Dijk (1980). Así intervienen el deseo de informar, analizar, explicar y criticar acercando los hechos al lector mediante expresiones fraseológicas verbales de la lengua actual dotadas de significado y caracterizadas por su contenido inferencial y su orientación pragmática en cada acto discursivo. En ellas concurren relaciones asociativas y de transposiciones semánticas, que son representativas y resultan llamativas y evocadoras, como se ve en (30) Los críticos del secretario general buscan la convocatoria inmediata de un congreso del PSOE, donde se pondrá en juego el liderazgo del partido (El País, 9/12/15).

Aparecen dos componentes léxico-fraseológicos en el ejemplo 30: uno, donde el verbo "buscar" va acompañado de un sustantivo "V+SN (CD)" que no le corresponde literalmente, aunque implícitamente se interpreta como una expresión unitaria con el significado de "forzar la convocatoria", y otro formado por "V pronominal+SPrep.", cuyo resultado es una expresión verbal pronominal "se pondrá en juego", que se interpreta no de modo literal equivalente a "arriesgar", sino metafórico con el sentido lingüístico-pragmático de "cuestionar".
Precisamente a través de los indicadores léxico-semánticos se recompone el conjunto de inferencias que permite descubrir el sentido metafórico y pragmático con que se emplean las expresiones fraseológicas.

Así pues, en el discurso periodístico se utilizan habitualmente una amplia variedad de expresiones fraseológicas y, dentro de ellas, destacan sobremanera las expresiones sintagmáticas verbales en forma de locuciones, colocaciones y enunciados verbales. Así a través de estos procedimientos el discurso periodístico favorece la configuración del léxico-fraseológico, al tiempo que contribuye a dinamizar la lengua usual por la capacidad de representar pensamientos convencionales fácilmente identificados por los alocutores (o intérpretes) al actuar de lectores, como se muestra en (31) El gobierno se ha cerrado a cal y canto en su reforma laboral (La SER, 25/05/12).

Puede observarse en el ejemplo 31 que la locución nominal "a cal y canto", unida al verbo "cerrar", constituye una estructura verbal que responde a la forma de cerrar un solar con un muro de piedra rodada y cal, aunque, a su vez, puede equivaler a una colocación en cuanto a que el verbo admite modificaciones en sus componentes asociados del tipo "se ha cerrado en banda" para referirse a que "se mantiene firme en su propósito".

\section{Conclusiones}

Los componentes léxico-fraseológicos, en general, y los verbales, en particular, se utilizan en el discurso periodístico como reflejo de la lengua usual, basada en asociaciones léxico-semánticas y en procedimientos de restricción léxico-semántica y de transposición semántica inherentes a la lengua. Los más frecuentes utilizados en el discurso periodístico son los verbales que conforman el predicado verbal ajustándose a alguno de estos tres tipos fraseológicos convencionales: locuciones, colocaciones y enunciados fraseológicos. Aunque teóricamente son diferentes en la formalización por la fijeza e idiomaticidad logradas, en la práctica los límites son difusos. 
Tanto las locuciones como las colocaciones coinciden en que son unidades fraseológicas suboracionales en cuanto a que carecen de autonomía; en cambio, los enunciados fraseológicos están dotados de independencia sintáctica. Además, las locuciones se caracterizan por la fijación, la idiomaticidad y la frecuencia de uso, a diferencia de las colocaciones que admiten variaciones o modificaciones y comparten con los sintagmas libres la ausencia de idiomaticidad. Puede decirse que el grado de adquisición de un significado figurado e integrador de los componentes que forman el predicado es lo que permite distinguir unas expresiones fijas o semifijas, como las locuciones y los enunciados fraseológicos, y otras que están en proceso de formalización al admitir variaciones, como las colocaciones.

La presencia constante del componente léxico-fraseológico en el discurso periodístico obedece esencialmente al propósito de seducir o captar el interés del lector mediante el recurso a las unidades léxicas sugerentes o llamativas tomadas de la lengua usual. Esto responde a la utilización de estrategias persuasivas, que contribuyen a la orientación pragmático-discursiva dirigida por el locutor-periodista a un intérprete colectivo con quien desea compartir ideas sobre la visión del mundo y la realidad. Al ser un procedimiento convencional y representativo de la lengua actual, es normal que el discurso periodístico recurra a todo tipo de estrategias lingüísticas y discursivas, como las combinaciones léxico-sintácticas -idiomáticas, semiidiomáticas o variacionales- que adquieren sentido y valor pragmático en cada actualización discursiva, aunque manteniendo el significado convencional compartido por la mayoría de hablantes de la comunidad lingüística. Precisamente, la fraseología forma parte del proceso de lexicalización en el que intervienen los usuarios de la lengua. Así pues, las expresiones fraseológicas constituyen estados intermedios en el proceso de lexicalización $\mathrm{y}$, cuando se fusionan los componentes, se convierten en unidades léxicas que conforman en su conjunto el componente léxico-fraseológico de la lengua.

\section{Bibliografía}

Alarcos Llorach, E. (1972). "Verbo transitivo, verbo intransitivo y estructura del predicado". En Estudios de Gramática funcional del español (pp. 109-123). Madrid: Gredos.

Blanco Escoda, X. (2000). "Verbos soporte y clase de predicados en español”. Lingüística española actual (LEA), 22/1, 99-118.

Bosque, I. (2001). “Sobre el concepto de 'colocación' y sus límites”. Lingüística Española Actual 23 (1), 9-40.

Casares, J. (1992). Introducción a la lexicografía moderna. Madrid: C.S.I.C.

Cervera Rodríguez, Á. (2014). "Análisis lingüísticopragmático de titulares de artículos de opinión. Revista Lingüística y Literatura”, n 66, 65-88. Colombia: Univ. de Antioquia.

Cervera Rodríguez, Á. (2013). "Marcas lingüísticas de orientación argumentativa en actos de habla del español”. En Ma ${ }^{\mathrm{a}}$. J. Fernández-Leborans y L. Martínez-Falero (Eds.). Lingüística, retórica y teoría de la literatura. (pp.57-70). Madrid: Arco libros.

Cervera Rodríguez, Á. (2013). Los enunciados del español en el discurso oral y escrito. Madrid: Eds. del Orto/Clásicas.

Corpas Pastor, G. (1996). Manual de fraseología española. Madrid: Gredos.

Corpas Pastor, G. (2000) (ed. e introd.). Las lenguas de Europa: estudios de fraseología, fraseografía $y$ traducción. Granada: Comares.

Corpas Pastor, G. (2003). Diez años de investigación en fraseología: Análisis sintáctico-semánticos, contrastivos y traductológicos. Madrid / Frankfurt am Main: Iberoamericana / Vervuert. 
Coseriu, E. (1986). "Las solidaridades léxicas". En Principios de semántica estructural (pp. 143-161). Madrid: Gredos.

Ducrot, O. (1984). Decir y no decir. Barcelona: Anagrama.

Di Tullio, Á. (1997). Manual de gramática del español. Buenos Aires: Edicial.

Elvira, J. (2006), "Aproximación al concepto de lexicalización”. En Diacronía, lengua española y lingüística. Actas IV Congreso JIHLE, (pp. 2142). Madrid.

Escandell Vidal, Ma V. (1991). "Sobre las reduplicaciones léxicas”. LEA, XIII, 71-86.

García-Page Sánchez, M. (200o). "Expresiones fijas idiomáticas, semiidiomáticas y libres”. Cahiers du prohemio, 3, 95-109.

García-Page Sánchez, M. (2001). “'Son las expresiones fijas expresiones fijas?” Moenia 7. 165-197.

García-Page Sánchez, M. (2008). Introducción a la fraseología española: estudio de las locuciones. Barcelona: Anthropos.

Harris, Z. S. (1976). Notes du cours de syntaxe, Paris: Le Seueil

Koike, K. (2001). Colocaciones léxicas en el español actual: estudio formal y léxico-semántico. Alcalá de Henares: Universidad de Alcalá de Henares.

Lakoff, G. y Johnson, M. (2001). Metáforas de la vida cotidiana. Madrid: Cátedra.

Maldonado, C. (1991). Discurso directo y discurso indirecto. Madrid: Taurus.

Martínez López, J. A. (1995). La fraseología del español. Acercamiento morfosintáctico, semántico y pragmático. Granada, Servicio de Publicaciones: Universidad de Granada.
Mellado Blanco, C. (2004). Fraseologismos somáticos del alemán. Frankfurt am Main: Peter Lang.

Nadal Palazón, J. (2009). El discurso ajeno en los titulares de la prensa mexicana. México: Universidad Autónoma de México.

Penadés Martínez, I. (2001). “Colocaciones o locuciones verbales?” En Lingüística española actual (LEA), Vol. 23, no 1, 57-88.

RAE y Asociación de academias de la lengua española (2009). Nueva gramática de la lengua española (NGLE). Madrid: Espasa Calpe, 2 vols.

Rivas González, M. (2004). “Tratamiento de las expresiones fraseológicas en los principales diccionarios de español. Propuesta para el aprendizaje de español como lengua extranjera". Actas XV Congreso ASELE (pp. 727-732). Centro Virtual Cervantes.

Romero Ganuza, P. (2007). "La delimitación de las unidades fraseológicas en la investigación alemana y español”. Interlingüística, $\mathrm{n}^{0}$ 17, 905-914.

Ruiz Gurillo, L. (1997a). Aspectos de fraseología teórica española. Cuadernos de Filología, Anejo XXIV. València: Universitat de València.

Ruiz Gurillo, L. (1997b). Relevancia y fraseología: la desautomatización en la conversación coloquial. En Español actual, 68, 21-30.

Ruiz Gurillo, L. (1998). La fraseología del español coloquial. Barcelona: Ariel.

Subirats Rüggeberg, C. (2001). Introducción a la sintaxis léxica del español. Madrid: Vervuert, Lingüística Iberoamericana.

Tesniére, L. (1966). Éléments de syntaxe structurale. Paris: Éditions Klinicksieck. 
Van Dijk, T.A. (1980). "Algunas notas sobre la ideología y la teoría del discurso". En Semiosis (pp. 37-53). México: Universidad Veracruzana, Xalapa.

Wotjak, G. (1998). Estudios de fraseología y fraseografía del español actual. Frankfurt am Main, Vervuert: Lingüística Iberoamericana.

Zuluaga, A. (1980). Introducción al estudio de las expresiones fijas. Frankfurt: V. Peter Lang.

Zuluaga, A. (1997). "Sobre las funciones de los fraseologismos en textos literarios”. Paremia, 6, 631-640.

Zuluaga, A. (2002). "Los enlaces frecuentes de María Moliner: observaciones sobre las llamadas colocaciones”. Lingüística Española Actual (LEA), vol. 24., 1, 97-114. 